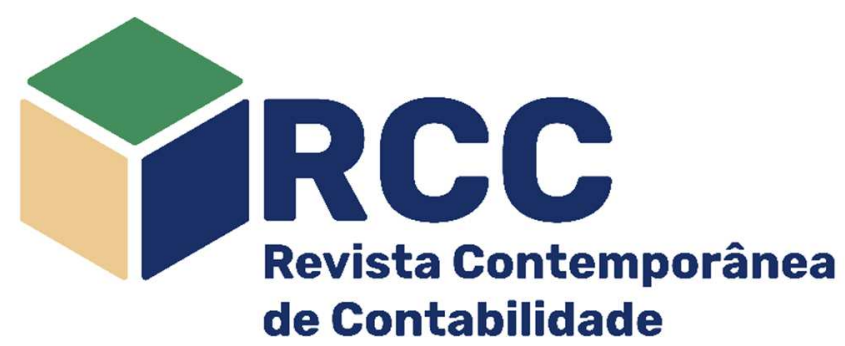

\title{
Do dano ao erário à inelegibilidade: uma análise das prestações de contas de gestores municipais de Goiás à luz de fatores ambientais
}

\author{
From Damage to the Treasury to the Ineligibility: An analysis of the accounts rendering of municipal \\ managers of Goiás in the light of environmental factors
} Del daño al erario a la inelegibilidad: un análisis de las prestaciones de cuentas de gestores
municipales de Goiás a la luz de factores ambientales

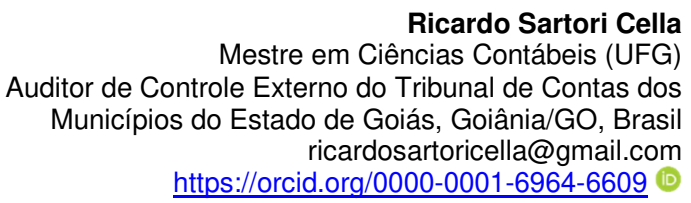

Ricardo Sartori Cella

Ciências Contábeis (UFG)

Municípios do Estado de Goiás, Goiânia/GO, Brasil

https://orcid.org/0000-0001-6964-6609 (D)

Endereço do contato principal para correspondência* Campus Samambaia - Prédio da FACE, Caixa Postal 131, CEP: 74.001-970, Goiânia, GO, Brasil

\section{Resumo}

O estudo objetiva identificar, a partir da análise do dano ao erário, quais são os fatores ambientais que impactam na probabilidade de gestores municipais serem incluídos na lista de inelegíveis. Para tanto, aplicouse da técnica de regressão logística em dados de 612 processos de prestação de contas, no período de 2008 a 2016. Os resultados indicaram que os fatores ambientais como distância de um município em relação à Capital e a prestação de contas correspondente ao ano eleitoral impactaram na inelegibilidade de gestores públicos municipais. Desse modo, os municípios localizados em regiões mais distantes da capital, ou seja, menos próximos da sede do Controle Externo, apresentaram maior probabilidade de terem seus gestores incluídos na lista de inelegíveis. Além disso, as prestações de contas de períodos que coincidiram com o ano de realização de eleições municipais evidenciaram ser mais propensas a ter uma maior chance de inelegibilidade dos gestores.

Palavras-chave: Inelegibilidade; Dano ao Erário; Prestação de Contas; Tribunal de Contas

\begin{abstract}
This study aims to identify from the analysis of damage to the treasury which are the environmental factors that impact on the probability of municipal managers being included in the ineligible list. For this, it was applied to the logistic regression technique to data from 612 accountability processes from 2008 to 2016 . Results show that environmental factors like the distance of a municipality in relation to the capital and rendering of accounts in the electoral year impact on the ineligibility of municipal public managers. Thus, municipalities located far from the capital, that is, less close to the Court of Accounts headquarters, showed more probability of managers being included in the ineligibility list. In addition, the rendering of accounts for periods that coincided with the year of municipal elections showed that they were more likely to have a greater chance of ineligibility for managers.

Keywords: Ineligibility; Damage to the treasury; Accountability; Court of Accounts

\section{Resumen}

O estudio tiene como objetivo identificar a partir del análisis del daño al erario cuáles son los factores ambientales que impactan en la probabilidad de que los gestores municipales sean incluidos en la lista de inelegibles. Para ello, se aplicó de la técnica de regresión logística en datos de 612 procesos de rendición de cuentas en el período de 2008 a 2016. Los resultados indicaron que factores ambientales como la distancia
\end{abstract}


de un municipio en relación con la capital y la rendición de cuentas correspondientes al año electoral impactaron la inelegibilidad de los administradores públicos municipales. De esta forma, los municipios ubicados en regiones más distantes de la capital, es decir, menos cercanas a la sede del Control Externo, tenían más probabilidades de incluir a sus gerentes em la lista de no elegibles. Además, la rendición de cuentas por períodos que coincidieron con el año de las elecciones municipales mostró que tenían más probabilidades de tener una mayor probabilidad de inelegibilidad para los gerentes.

Palabras clave: Inelegibilidad; Daño al Erario; Rendición de cuentas; Tribunal de Cuentas

\section{Introdução}

Para que as necessidades básicas da sociedade sejam supridas, o Estado deve manter uma estrutura patrimonial que contemple o aparelhamento necessário para a disponibilização de serviços públicos. Sem esses serviços, o cidadão estaria à mercê da própria sorte ou da própria capacidade quanto ao provimento das demandas prioritárias relacionadas à saúde, educação, segurança, assistência e previdência social, entre outras que não deixam de ter uma importância relativa na escala das necessidades humanas.

Segundo Arato (2002), a existência de uma Constituição que assegura direitos é o cerne para a garantia da soberania popular, ou seja, no regramento são reservados poderes aos cidadãos para que estes usufruam a liberdade de escolha de seus representantes. Esse direito, que é classificado como político na Constituição Federal, possibilita o exercício pleno da soberania popular através do voto, que é o instrumento de depósito da confiança no propósito de um representante, para que este desenvolva ações em prol dos interesses da coletividade, com a utilização dos recursos da máquina pública para o fornecimento de bens e serviços à população. Espera-se que este representante eleito coloque em prática a vontade do povo.

O objetivo primordial das entidades do setor público é fornecer serviços que atendam às necessidades básicas da sociedade no sentido de aprimorar ou manter os padrões de bem-estar relacionados aos programas e políticas de saúde, educação, segurança, entre outros (Conselho Federal de Contabilidade - CFC, 2016). Assim, para atender ao seu objetivo, os entes públicos necessitam manter uma estrutura patrimonial que possibilite disponibilizar os serviços demandados pela população.

A gestão desse patrimônio envolve o uso de recursos de natureza pública e, como tal, há o dever constitucional da prestação de contas. Para que possa ser compreendida, a prestação de contas necessita ser apresentada por intermédio de uma estrutura de relatório. Os Relatórios Contábeis de Propósito Geral das Entidades do Setor Público são os componentes principais da tomada de decisão, da transparência da informação contábil, da prestação de contas e da accountability) e visam atender às necessidades dos usuários gerais dos serviços, de seus representantes e também dos provedores de recursos (CFC, 2016).

Como se pode perceber, o objetivo básico da Contabilidade é prover o cidadão de informações relevantes que possam servir para a tomada de decisão (AMERICAN ACCOUNTING ASSOCIATION, 1977). Ressalte-se, ainda, que é o ramo da Contabilidade Pública que pode fornecer informações úteis capazes de influenciar a escolha dos representantes pelos eleitores, que se tornam mais esclarecidos quanto às consequências das políticas públicas e práticas de finanças adotadas pelos governantes (INGRAM; COPELAND, 1981). Com base nessas informações, o cidadão pode decidir entre manter ou substituir um representante político.

Nessa perspectiva, Lane (2013) observa que a abordagem principal-agente se encaixa perfeitamente no processo de políticas públicas, sendo que o gestor público ocupa o papel de agente e tem uma necessidade ilimitada de recursos para manter sua posição de destaque na sociedade. A população atua como principal, escolhe um representante com base em suas afinidades e demais preferências pessoais, e espera que o eleito atue em favor do interesse público, em respeito da ética, de forma transparente e de acordo com os princípios básicos da legalidade, impessoalidade, moralidade, publicidade e eficiência. Nessa esteira, a prestação de contas é o elo entre o gestor público e a população (PEREIRA; CORDEIRO FILHO, 2012).

É nessa relação eleitor-representante que se insere a importância social das Entidades de Fiscalização Superiores (EFS) como mecanismo de monitoramento das ações dos agentes, atuando em prol do controle da corrupção e do patrimônio público, da promoção da transparência, ampliação da accountability e da defesa da democracia. Essa importância também pode ser destacada através de estudos sobre EFS que vem sendo desenvolvidos nos últimos vinte anos, tanto por parte de pesquisadores internacionais quanto nacionais.

Considerando que os Tribunais de Contas nacionais têm como função a análise da prestação de contas dos responsáveis por dinheiros públicos, a Lei Complementar n. 135/10 (Ficha Limpa) atribui às Cortes de Contas outra grande responsabilidade, que é a de identificar o rol dos agentes que poderiam ser barrados do processo eleitoral, em razão da prática de atos contrários ao interesse público (BRASIL, 2010).

Assim, ao julgar a prestação de contas desses responsáveis por dinheiros públicos, o Tribunal de Contas pode concluir pela regularidade ou pela irregularidade. Em caso de rejeição, amparado na Lei Federal n. 9.504/97 (BRASIL, 1997), o Tribunal de Contas deve encaminhar à Justiça Eleitoral, a cada ano eleitoral, a lista dos agentes que tiveram suas contas rejeitadas por irregularidade insanável ou por decisão não recorrível do órgão competente (BRASIL, 2010). 
Esta pesquisa justifica-se por trazer contribuições de ordem teórica na área do controle externo. Para Pollit e Summa (1997), mesmo que as Entidades Fiscalizadoras Superiores desempenhem um importante papel no plano político e administrativo dos seus países, não são objeto de grande interesse por parte dos pesquisadores.

No contexto apresentado, formula-se o seguinte problema de pesquisa: a partir da análise do dano ao erário, quais são os fatores ambientais que impactam na probabilidade de gestores municipais do Estado de Goiás serem incluídos na lista de inelegíveis?

Desse modo, o objetivo desta pesquisa é verificar, a partir da análise do dano ao erário, quais são os fatores que impactam na probabilidade de gestores municipais do Estado de Goiás serem incluídos na lista de inelegíveis.

\section{Revisão de Literatura e Hipóteses de Pesquisa}

\subsection{A Relação de Agência na Administração Pública}

A relação principal-agente é geral e se faz presente nas mais diversas organizações, inclusive na administração pública (JENSEN; MECKLING, 1976; KELLY, 1998). No âmbito da administração pública o agente político do governo articula a política pública, define os padrões de desempenho e escolhe um agente para, em nome do governo, ofertar bens e serviços para que os objetivos sejam alcançados (Kelly, 1998. Dessa forma, a relação de agência é perceptível no Estado democrático, pois os cidadãos elegem um representante político, que norteará as políticas públicas de interesse da sociedade a serem desempenhadas, por delegação, por agentes executores da administração interna ou contratados diretamente junto ao mercado. Segundo a autora, para que essa sistemática seja concretizada, a política a ser implementada, as linhas de responsabilidade adotadas pelos participantes e os padrões de desempenhos a serem alcançados precisam ser muito claros e fiéis aos objetivos propostos. Se esses pressupostos forem satisfeitos, o agente alcançará o objetivo do interesse público.

Streim (1994) classifica a relação principal-agente no setor público em três tipos: a relação entre o eleitor (principal) e os representantes políticos (agente), a relação entre o legislador (principal) e o governo (agente) e a relação entre o governo (principal) e a burocracia (agente). Considerando o enfoque da presente pesquisa, a relação entre eleitor e representante merece maior destaque. A relação entre cidadãos e políticos eleitos se refere ao processo democrático no qual os eleitores escolhem seus representantes para que estes implantem políticas públicas em prol do bem-estar da coletividade.

Para Calabro e Torchia (2011), os cidadãos são o principal e os governos locais atuam como representantes do interesse público. Por serem proprietários dos bens públicos, os cidadãos delegam autoridade a um membro ou grupo dessa organização social, para que tomem decisões sobre o uso desses bens, mediante um contrato implícito (AGHION; TIROLE, 1997).

Assim, os cidadãos atuam na posição de principal, pois são os titulares da soberania e podem escolher e controlar os representantes; os políticos eleitos ou gestores públicos atuam como agentes, mas em razão do poder coercitivo do Estado podem impor obrigações aos cidadãos (PEREIRA; SPINK, 2014). Segundo os autores, porém, um dos grandes problemas para os cidadãos é fazer com que os políticos abandonem seus interesses particulares para agirem em defesa da sociedade. Isso, em parte, é justificado pela delegação de autoridade, que necessariamente envolve uma perda de controle por parte do principal (AGHION; TIROLE, 1997).

Nessa lógica, se os agentes tiverem como prioridade a satisfação de desejos pessoais, não desenvolverão as ações almejadas pela sociedade e, se os eleitores não tiverem acesso a informações úteis para avaliar a gestão e cobrar o interesse da coletividade, o poder de escolha do melhor representante tornase prejudicado (MANIN; PRZEWORSKI; STOKES, 2006). Assim, a influência sobre o agente depende da completude da informação. Aghion e Tirole (1997) destacam que o principal tem a autoridade formal para alterar a decisão de um agente, mas o principal irá abster-se de interferir no processo decisório se o agente estiver mais bem informado que o próprio principal.

Desse modo, é perceptível que o conflito de interesses é inerente à relação de agência no âmbito da administração pública. Para Boyce e Davids (2009), um conflito de interesses nessa esfera é qualquer conflito entre os interesses pessoais, privados, financeiros ou não financeiros de um funcionário público e o seu dever de atuar em prol do interesse público. Os autores complementam que os interesses pessoais ou privados incluem os membros da família, amigos, sócios, organizações às quais o agente pertença e outros interesses similares. No que se refere aos interesses financeiros, os autores citam o recebimento ou a posse de dinheiro e bens e as atividades comercias privadas; e os interesses não financeiros se referem às influências, lealdades, preconceitos, crenças, afiliações partidárias, inimizade em relação a indivíduos ou grupos, entre outros fatores.

O conflito de interesses surge de um comportamento não ético no serviço público e é um dos fatores que contribui para o declínio do padrão de conduta das organizações estatais (CALABRIO; TORCHIA, 2011; BOYCE; DAVIDS, 2009). Essa queda de padrão de conduta diz respeito à redução da qualidade da administração pública, da responsabilidade pública, da confiança dos cidadãos em relação aos governos, 
instituições e funcionários públicos, da fragilização da integridade do setor público e do sistema democrático, de forma mais ampla (BOYCE; DAVIDS, 2009). Entretanto, o conflito de interesses presente na relação principal-agente pode ser amenizado através de mecanismos de monitoramento (JENSEN; MECKLING, 1976; STREIM, 1994; HEFETZ; WARNER, 2004).

\subsection{Formulação das hipóteses de pesquisa}

A perspectiva ambiental da pesquisa advém da relação entre o gestor e o eleitor (sociedade). A partir dessa premissa, serão construídas as hipóteses de pesquisa, que permitirão compreender quais as variáveis ambientais que conduzirão a um aumento ou redução da probabilidade de inclusão dos agentes púbicos na lista de inelegíveis. Partindo de elementos característicos do meio (município) no qual o eleitor está inserido, ou seja, dos fatores socioeconômicos, físicos ou de influência sobre o eleitor (eleições municipais) presentes em cada município será possível identificar em qual contexto municipal os interesses do agente podem se distanciar do principal. Esse distanciamento tem como ápice o dano ao patrimônio público.

Segundo Kronbauer et al. (2011), as métricas ambientais possuem relação com a quantidade de irregularidades nas contas públicas. Nessa lógica, a introdução de variáveis como tamanho do município, distância do município até a capital, Índice de Desenvolvimento Humano municipal (IDHm) e ano de eleições municipais, que serão descritas mais à frente, permitirão a verificação da probabilidade de inelegibilidade dos gestores públicos municipais.

Alguns autores adotam como referência a população municipal para mensurar a dimensão do tamanho de um município. Kronbauer et al. (2011) identificaram que há uma maior probabilidade de apontamentos de irregularidades pelo órgão de controle externo nas cidades com maior população, porém, os autores não encontraram uma relação significativa. Laureano (2016), também evidenciou uma relação positiva entre o tamanho da população e a ocorrência de irregularidades na gestão municipal, mas os resultados não foram estatisticamente significativos.

Em outra temática, Milanezi e Monte-Mor (2017) também não encontraram relação significativa entre a população e a reprovação das contas quando da utilização de créditos adicionais. Albuquerque (2016), ao analisar a influência da população no julgamento pela irregularidade das contas, também não identificou significância estatística nessa relação.

A conclusão apresentada nesses trabalhos citados é a de que o tamanho da população está associado com a ocorrência de irregularidades, mas a não significância dos resultados leva à necessidade de realização de novos estudos. Os autores revelam a relação positiva entre as variáveis, mas os achados não possuem significância estatística. Provavelmente, uma alternativa seria estudar a variável população, mas com outro enfoque, o que permitiria preencher uma lacuna deixada nas pesquisas. Este novo enfoque seria analisar a influência da variável população eleitoral, o que vai ao encontro da relação entre gestor e eleitor.

Diante dos estudos já realizados, bem como do indicativo de que o tamanho da população influencia na quantidade de irregularidades das contas municipais, propõe-se que o tamanho da população eleitoral está positivamente associado à inclusão de agentes públicos na lista de inelegíveis. Assim sendo, sugere-se a hipótese:

\section{H1 - Quanto maior o tamanho da população eleitoral, maior é a probabilidade da inclusão do gestor na lista de inelegíveis.}

A variável distância pode ser analisada sob duas vertentes. Segundo Campante e Do (2014), as cidades que estão mais distantes da capital estão associadas a níveis mais altos de corrupção e menor accountability. Além disso, a proximidade geográfica de órgãos fiscalizadores permite que unidades fiscalizadas sejam melhor avaliadas em razão do lobby dos gestores e da maior interação entre os membros dos entes fiscalizadores e gestores (DU; TANG; YOUNG, 2012).

Considerado que a sede do Tribunal de Contas dos Municípios do Estado de Goiás (TCMGO), que é o órgão de controle externo municipal do Estado de Goiás, fica localizada na capital Goiânia, a distância de cada município até a capital pode ser um indicativo de ocorrência de um maior número de irregularidades. Ou, fazendo uma analogia à visão e Du, Tang e Young (2012), a proximidade dos munícipios em relação ao órgão de controle pode favorecer o lobby dos Prefeitos perante a Corte de Contas e seus membros julgadores. Essa maior interação entre membros e gestores permitiria, provavelmente, um julgamento mais brando em semelhança à melhor avaliação identificada por Du, Tang e Young (2012).

Dessa forma, espera-se que uma menor distância em relação à capital favoreça a não inclusão na lista de inelegíveis e em contrapartida, uma maior distância contribua para o aumento da probabilidade de inclusão dos agentes públicos na lista. Logo, a relação entre a distância e a inclusão na lista é positiva, razão pela qual surge a seguinte hipótese de pesquisa:

H2 - Quanto maior é a distância do município em relação ao órgão de Controle Externo, maior é a probabilidade de inclusão do gestor na lista de inelegíveis. 
Outros estudos que abordaram a temática da irregularidade das contas e permitiram identificar que a incidência de irregularidades aumenta quando as características socioeconômicas dos municípios são desfavoráveis (KRONBAUER; KRÜGER; OTT; NASCIMENTO, 2011; SANTOS; PIMENTA; RANGEL; OHAYON, 2016; ALBUQUERQUE, 2016). Entretanto, como os autores apresentaram resultados contraditórios, abre-se espaço para a realização de novos estudos.

Kronbauer et al. (2011) não encontraram resultados significativos associados entre o Índice de Desenvolvimento Humano (IDH) e irregularidade na prestação de contas. Por outro lado, Santos et al. (2016) e Albuquerque (2016) verificaram que municípios com maior Índice de Desenvolvimento Humano Municipal (IDHm) apresentam um maior número de falhas nas prestações de contas que ensejam o apontamento de ressalvas nos pareceres.

No que se refere ao Índice de Desenvolvimento Humano Municipal (IDHm), nesta pesquisa será adotada a perspectiva de Kronbauer et al. (2011). Os autores verificaram que os nos municípios gaúchos localizados nas regiões onde o IDHm é menor há uma maior incidência de inconformidades. Nesse sentido, deduz-se que o quantitativo de irregularidades aumenta em municípios com menor IDHm, o que favorece a inclusão de agentes na lista de inelegíveis.

Como um maior IDHm representa uma melhor condição socioeconômica municipal, a relação é negativa ou inversa, de modo que se sugere a hipótese:

\section{H3 - Quanto menor é o IDHm municipal, maior é a probabilidade da inclusão do gestor na lista de inelegíveis.}

A variável ano eleitoral representa outro fator que pode estar relacionado à probabilidade de inclusão dos agentes na lista de inelegíveis. $O$ ano eleitoral é pouco abordado nas pesquisas sobre análise de irregularidades na prestação de contas. Esse fato justifica a ampliação das pesquisas bem como o estudo de sua influência, especificamente no Estado de Goiás onde o tema permanece inexplorado.

Segundo Pereira (2010), a proporção de rejeição das contas aumenta em anos eleitorais, quando comparados com períodos para os quais não ocorrem eleições municipais. Além disso, Ribeiro Filho (2011) identificou que em anos eleitorais há um aumento dos investimentos e despesas de capital, ou seja, realização de obras públicas que geram impacto na opinião do eleitor. Além disso, o autor analisou o comportamento da proporção da receita financeira em ano eleitoral. $\mathrm{O}$ estudo indicou que a proporção de receita tributária tende a reduzir em ano eleitoral com uma forma de agradar o eleitor, revelando o comportamento oportunista dos prefeitos nesses períodos de pleito.

Para Pereira e Cordeiro Filho (2012), fatores como ano eleitoral e tamanho do município podem ditar as regras da execução do orçamento público e, assim, aumentar as chances de rejeição das contas públicas. Nesse sentido, o ambiente proporcionado pelo ano eleitoral pode ser um fator condicionante para a rejeição das contas e para a inclusão de gestores no rol de inelegíveis, logo a relação é positiva. Portanto, formula-se a seguinte hipótese de pesquisa:

\section{H4 - O ano eleitoral aumenta a probabilidade da inclusão do gestor na lista de inelegíveis.}

\section{Metodologia}

\subsection{População e Coleta dos Dados}

A pesquisa tem como população a totalidade dos processos de prestação de contas de gestão dos Poderes Executivos de todos os 246 municípios do Estado de Goiás, autuados entre 2008 e 2016 no Tribunal de Contas de Municípios do Estado de Goiás (TCMGO), e que tenham sido julgados até 08/07/2016 (TCMGO, 2016), marco temporal para inclusão na lista de inelegíveis do Tribunal Regional Eleitoral do ano de 2016 (TRE-GO, 2016). Partiu-se de um universo de 1.272 processos de contas de gestão de poderes executivos municipais julgados irregulares. Foram excluídos 621 processos para os quais não houve imputação de débito e mais 39 processos com julgamentos posteriores a data limite para inclusão na lista de inelegíveis.

Após as exclusões, chegou-se à amostra da pesquisa que consiste em 612 processos dos poderes executivos municipais do Estado de Goiás, autuados no Tribunal de Contas dos Municípios do Estado de Goiás entre 2008 e 2016, vinculados a 240 municípios distintos, e que em decorrência do julgamento da Corte tiveram o julgamento pela irregularidade, com imputação de débito na decisão de mérito, conforme Tabela 1:

Tabela 1 - Resumo da Seleção da Amostra de Processos

$\begin{array}{lc}\text { Universo inicial: Processos do Poder Executivo (Contas Mensais de Gestão) autuados } & 1.272 \\ \text { entre } 2008 \text { e 2016) } & (621) \\ \text { (-) Processos sem imputação de Débito } & (39) \\ \text { (-) Processos com decisão de mérito após 08/07/2016 } & 612 \\ \text { (=) Amostra (Processos de Contas de Gestão do Poder Executivo com Débito) }\end{array}$

Fonte: Elaborada pelos autores, a partir dos dados da pesquisa. 
Para cada processo da amostra, foram identificados os respectivos gestores com julgamento pela irregularidade das suas contas e com imputação de débito. Após esta etapa, esta base de dados levantada junto ao TCMGO foi comparada com a relação de inelegíveis do Tribunal Regional Eleitoral do Estado de Goiás (TRE-GO) do ano de 2016. Verificou-se nominalmente se cada um dos responsáveis com imputação de débito nos processos de prestação de contas estava relacionado na lista de inelegíveis. Da análise, constatou-se a ocorrência de 248 observações de inclusão dos agentes na lista e 410 observações de não inclusão na lista. O total de observações (658) supera a quantidade de processos da amostra (612) porque alguns processos tiveram mais de um responsável com imputação de débito. Isso é justificável pela troca de gestores ao longo de um mesmo ano. Desse modo, cada gestor responsabilizado em um determinado processo foi considerado como uma observação distinta, em razão da lista de inelegíveis ser nominal e não apenas processual.

Para responder a cada uma das hipóteses da pesquisa também foram levantados os dados relativos às características de cada município contemplado nos processos de julgamento de contas da amostra selecionada. Desse modo, foram coletadas as informações referentes ao tamanho da população eleitoral, a distância do município em relação à capital do Estado de Goiás (Goiânia), a medida do Índice de Desenvolvimento Humano Municipal e se 0 ano de referência da prestação de contas coincidia com a realização de eleições municipais. O Quadro 1 apresenta um breve resumo das variáveis compiladas na base de dados, bem como o sinal esperado em relação a cada uma das hipóteses de pesquisa:

Quadro 1 - Definição das Variáveis Utilizadas na Pesquisa

\begin{tabular}{|c|c|c|c|c|}
\hline \multicolumn{5}{|c|}{ VARIÁVEL DEPENDENTE } \\
\hline Variável & Nome & \multicolumn{3}{|l|}{ Descrição e Mensuração } \\
\hline Ineleg & Inelegível & \multicolumn{3}{|c|}{$\begin{array}{l}\text { Variável binária. Representa a inclusão ou não do agente público na lista de } \\
\text { inelegíveis do TRE-GO para o período eleitoral de } 2016 \text { (eleições municipais). A } \\
\text { partir dos processos com imputação de débito na decisão de mérito, assume o } \\
\text { valor } 1 \text { se o agente público foi incluído na lista de inelegíveis e } 0 \text { se não houve a } \\
\text { inclusão. } \\
\text { Fonte: Tribunal Regional Eleitoral do Estado de Goiás (TRE-GO, 2016) }\end{array}$} \\
\hline \multicolumn{5}{|c|}{ VARIÁVEIS AMBIENTAIS (RELAÇÃO GESTOR-ELEITOR) } \\
\hline Variável & Nome & Descrição e Mensuração & $\begin{array}{c}\text { Sinal } \\
\text { Esperado }\end{array}$ & $\begin{array}{c}\text { Hipótese } \\
\text { de } \\
\text { Pesquis } \\
\text { a }\end{array}$ \\
\hline Tam & $\begin{array}{l}\text { Tamanho } \\
\text { População } \\
\text { Eleitoral }\end{array}$ & $\begin{array}{l}\text { Variável quantitativa e de característica do município. } \\
\text { Representa o tamanho da população eleitoral do ano } \\
\text { da prestação de contas de cada município do Estado } \\
\text { de Goiás no período de } 2008 \text { a } 2016 \text {. Para a população } \\
\text { será calculado o valor do logaritmo natural (In) do } \\
\text { número de eleitores correspondente ao ano de } \\
\text { referência da prestação de contas. } \\
\text { Fonte: Instituto Mauro Borges (IMB, 2017) }\end{array}$ & $(+)$ & $\mathrm{H} 1$ \\
\hline Dist & $\begin{array}{l}\text { Distância até a } \\
\text { Capital }\end{array}$ & $\begin{array}{l}\text { Variável quantitativa e de característica do município. } \\
\text { Representa a distância em quilômetros entre o } \\
\text { município do processo de contas e a Capital do Estado } \\
\text { de Goiás (Goiânia), ou seja, a distância em relação à } \\
\text { sede do Tribunal de Contas dos Municípios do Estado } \\
\text { de Goiás. Nesta pesquisa, a distância até a Capital foi } \\
\text { considerada a mesma em todos os anos. } \\
\text { Fonte: Instituto Mauro Borges (IMB, 2017). }\end{array}$ & $(+)$ & $\mathrm{H} 2$ \\
\hline$I D H m$ & $\begin{array}{l}\text { Índice de } \\
\text { Desenvolvimento } \\
\text { Humano } \\
\text { Municipal }\end{array}$ & $\begin{array}{l}\text { Variável quantitativa e de característica do município. } \\
\text { Representa o Índice de Desenvolvimento Humano } \\
\text { Municipal e corresponde ao grau de desenvolvimento } \\
\text { econômico e a qualidade de vida oferecida à } \\
\text { população municipal. Para essa variável serão } \\
\text { utilizados valores individualizados por município, mas } \\
\text { fixos para todos anos, tendo por base o último } \\
\text { levantamento do censo do IBGE do ano de } 2010 \text {. } \\
\text { Fonte: Instituto Mauro Borges (IMB, 2017) }\end{array}$ & $(-)$ & H3 \\
\hline AnoE & Ano Eleitoral & $\begin{array}{l}\text { Variável binária. Representa o ano em que são } \\
\text { realizadas as eleições municipais. Assume valor um } \\
\text { no ano em que foram realizadas eleições municipais } \\
(2008,2012,2016) \text { e zero nos demais }(2009,2010 \text {, } \\
2011,2013,2014,2015) \text {. } \\
\text { Fonte: Tribunal Superior Eleitoral (TSE, 2016) }\end{array}$ & $(+)$ & $\mathrm{H} 4$ \\
\hline
\end{tabular}

Fonte: Elaborada pelos autores. 
foram levantados junto ao Instituto Mauro Borges (IMB, 2017). O tamanho da população eleitoral correspondeu ao número de eleitores do ano da prestação de contas, normalizado pelo valor do logaritmo natural desta população eleitoral, em razão da variância que os dados populacionais apresentaram em decorrência dos portes dos municípios. Para a medida da distância em relação à capital, foi considerada mesma distância em todos os anos, independente do ano da prestação de contas, por serem dados físicos sem alterações significativas ao longo dos anos de estudo e por não possuírem dados concretos sobre a variação dessas distâncias no decorrer dos anos, em razão da construção e conclusão de novas rodovias. Para o Índice de Desenvolvimento Humano foi adotado o valor do último censo realizado pelo Instituto Brasileiro de Geografia e Estatística em 2010 para cada município do respectivo e processo de prestação de contas da amostra.

O ano eleitoral foi apurado junto ao Tribunal Superior Eleitoral (TSE, 2016), e corresponde aos anos para os quais foram realizadas eleições municipais. Comparou-se o ano da prestação de contas de cada processo com o calendário de eleições municipais. Para cada ano correspondente a eleição municipal adotouse o valor um, e zero para os demais períodos. Adotados os critérios acima expostos, nenhuma observação apresentou dados ausentes, que necessitassem a adoção de ajustes aritméticos.

\subsection{Tratamento Estatístico}

O fenômeno de estudo corresponde à análise dos fatores que levam a inclusão de agentes públicos na lista de inelegíveis. Nesse sentido, a variável de interesse que diz respeito ao fenômeno da inclusão na lista de inelegíveis é uma única variável dependente qualitativa dicotômica, de uma única categoria que pode assumir os valores binários (variável dummy) de 0 (não ocorrência do evento $=0$ ) e 1 (ocorrência do evento $=1)$.

De acordo com Fávero (2017), o modelo a ser utilizado com a presença de variáveis dependentes dicotômicas é o de regressão logística binária. Nesse mesmo sentido, Hilbe (2009) explica que a regressão logística possibilita a compreensão de uma resposta binária a partir de um ou mais fatores explicativos.

Para a realização do estudo atinente à inclusão na lista de inelegíveis foi desenvolvido o modelo descrito pela equação 1:

$$
P(\text { Ineleg }, 1)=\frac{1}{1+e^{-\left(+\beta_{2} \text { Dist }_{i, t}+\beta_{3} \operatorname{IDHm}_{i, t}+\beta_{4} \operatorname{AnoE}_{i, t}+\varepsilon_{i, t}\right)}}
$$

Onde,

i é o município do processo de prestação de contas;

$t$ é o exercício financeiro da prestação de contas de gestão do Poder Executivo Municipal vinculado a um processo do TCMGO;

$\beta_{0}$ é a constante;

$\beta_{1}$ a $\beta_{4}$ são os coeficientes das variáveis ambientais correspondente às características municipais;

Ineleg é a variável de interesse dependente, que se refere à inclusão ou não dos agentes públicos na lista de inelegíveis;

Tam é a população eleitoral de cada município do Estado de Goiás.

Dist é a distância do município em relação a Capital do Estado de Goiás.

$I D H m$ é o Índice de Desenvolvimento Humano Municipal.

$A n o E$ representa o ano em que são realizadas as eleições municipais.

$\varepsilon$ é o erro estatístico.

\section{Análise e Discussão dos Resultados}

\subsection{Análise Descritiva}

Inicialmente, apresentam-se os resultados obtidos por meio de análise descritiva dos dados das variáveis explicativas. A Tabela 2 exibe o número de observações, a mensuração das médias, desviospadrões, valores mínimos e máximos e os resultados dos testes estatísticos utilizados nas análises das variáveis independentes, separadas por grupos de agentes que foram incluídos na lista de inelegíveis comparados com aqueles que não foram incluídos na lista. Para fins de comparação das médias entre aos dois grupos utilizou-se os testes de Wilcoxon-Mann-Whitney e Qui- quadrado (FÁVERO, 2017). Esses resultados prévios da análise descritiva permitirão antecipar alguns resultados do modelo de regressão logística.

Com base na Tabela 2, o teste de Wilcoxon-Mann-Whitney aplicado às variáveis Tam e Dist evidencia que há uma diferença significativa entre os dois grupos, pois o $p$-valor resultou inferior a 0,05 para ambas as variáveis. Em razão disso, rejeita-se a hipótese nula de que não existem diferenças entre os dois grupos 
Tabela 2 - Estatísticas Descritivas das Variáveis (por Grupo)

\begin{tabular}{cccccc}
\hline \multirow{2}{*}{ Grupos } & \multirow{2}{*}{ Estatísticas } & \multicolumn{3}{c}{ Variáveis } \\
\cline { 3 - 6 } & $\mathrm{n}$ & Tam & Dist & IDHm & AnoE \\
\hline \multirow{4}{*}{ Inelegíveis (não) } & $\mu$ & 410 & 410 & 410 & 410 \\
& $\sigma$ & 9,243752 & 218,0268 & 0,699178 & 0,297561 \\
& $\min$ & 6,2483462 & 135,4279 & 0,031961 & 0,457744 \\
& máx & 13,71126 & 0 & 0,584 & 0 \\
Inelegíveis (sim) & $\mathrm{n}$ & 248 & 680 & 0,799 & 1 \\
& $\mu$ & 8,933582 & 266,0484 & 0,6932944 & 0,4959677 \\
& mín & 1,030744 & 139,9116 & 0,0354677 & 0,5009948 \\
& máx & 13,782192 & 0 & 0,584 & 0 \\
Testes (p-valor) & WMW & 0,0054 & 630 & 0,799 & 1 \\
\hline
\end{tabular}

Nota: Tam é o logaritmo natural da população eleitoral; Dist é a distância do município até a capital; IDHm é o índice de desenvolvimento humano municipal; AnoE corresponde ao ano eleitoral (1-sim; 0-não), $n$ é o número de observações, $\mu$ é média de cada variável por grupo, $\sigma$ é desvio-padrão de cada variável por grupo, mín é o valor mínimo de cada variável por grupo, máx é o valor máximo de cada variável por grupo, WMW é o teste de Wilcoxon-Mann-Whitney e Chi2 é o teste do Qui-quadrado e, para as variáveis.

Fonte: Elaborada pelos autores.

Como as variáveis Tam e Dist apresentaram diferenças significativas entre as médias dos dois grupos, é possível fazer algumas inferências acerca da inclusão dos agentes públicos na lista dos inelegíveis. A média da variável Dist é superior no grupo de agentes que foram incluídos na lista de inelegíveis em comparação aos que não foram incluídos. Ou seja, para os agentes que foram incluídos na lista, os respectivos municípios estão localizados mais distantes da capital. Por outro lado, a média da variável Tam é inferior no grupo de agentes que foram incluídos na lista de inelegíveis em comparação aos que não foram incluídos. Desse modo, os municípios dos agentes que foram incluídos na lista de inelegíveis apresentaram uma menor população eleitoral.

No que se refere à variável IDHm, o teste de Wilcoxon-Mann-Whitney resultou em um p-valor de 0,0747 , que é superior ao nível de significância de $5 \%(0,05)$, ou seja, não é significativo. Portanto, o resultado do teste não permite rejeitar a hipótese nula de que não há diferenças de médias entre os dois grupos. Dessa forma, o IDHm não se mostra ser um fator influente para a distinção entre os dois grupos.

Como a variável $A n o E$, é qualitativa e binária (pode assumir valor zero ou um) foi aplicado o teste do Qui-quadrado, que apresentou um p-valor significativo de 0.0000 , ou seja, inferior a 0,05. Este parâmetro possibilitou a rejeição da hipótese nula de que as frequências esperadas para a inclusão dos agentes públicos são iguais. Nesse caso, a média do ano eleitoral resultou superior no grupo de agentes incluídos na lista de inelegíveis, sendo o resultado significativo. Portanto, com base nos dados desta pesquisa, infere-se que o ano eleitoral é um fator contributivo para a inclusão dos agentes públicos na lista de inelegíveis.

\subsection{Regressão Logística}

O modelo de regressão logística para mensuração da probabilidade de inclusão dos agentes públicos na lista de inelegíveis é composto pela variável dependente Ineleg e pelas variáveis explicativas Tam, Dist, $I D H m$ e AnoE. Na Tabela 3 são apresentados os resultados do modelo de regressão logística, a partir do estimador logit.

Tabela 3 - Resultados da Estimação do Modelo de Mensuração de Probabilidade de Inelegibilidade

\begin{tabular}{cccccc}
\hline $\begin{array}{c}\text { Variáveis } \\
\text { Dependentes }\end{array}$ & $\begin{array}{c}\text { Sinal } \\
\text { Esperado }\end{array}$ & Valor do Coeficiente & $\begin{array}{c}\text { Desvio- } \\
\text { Padrão }\end{array}$ & Z & P-valor (z) \\
\hline Tam & + & $-0,1650311^{* *}$ & 0,0810504 & {$[-2,04]$} & $(0,042)$ \\
Dist & + & $0,0024548^{* * *}$ & 0,0006464 & {$[3,80]$} & $(0,000)$ \\
IDHm & - & $-0,2012193$ & 2,812194 & {$[-0,07]$} & $(0,943)$ \\
AnoE & + & $0,8676894^{* * *}$ & 0,1712884 & {$[5,07]$} & $(0,000)$ \\
Constante & $?$ & 0,2009914 & 1,895352 & {$[0,11]$} & $(0,916)$ \\
\hline Obs. & & & & 658 \\
\hline LR chi2(7) & & & & 51,20 \\
\hline LR (p-valor) & & & & 0,0000 \\
\hline Hosmer-Lemeshow (GOF)
\end{tabular}

Em que: Tam é o logaritmo natural da população eleitoral; Disté a distância do município até a capital; IDHm é o índice de desenvolvimento humano municipal; $A n o E$ corresponde ao ano eleitoral (1-sim; 0-não).

Nível de significância: ${ }^{* *} 1 \%,{ }^{*} 5 \%$. Valores do teste $z$ entre colchetes; P-valor da estatística $z$ entre parênteses.

Fonte: Elaborada pelos autores. 
A Tabela 3 apresentou os resultados da estimação do modelo de mensuração de probabilidade de inelegibilidade. Percebe-se que o modelo de regressão logística apresentou valores significativos para o teste da razão da verossimilhança (LR). Considerando que o $p$-valor do teste da razão da verossimilhança $(0,0000)$ é inferior a 0,0001, conclui-se que há pelo menos uma variável explicativa que possui parâmetro com significância estatística, ou seja, os parâmetros da regressão logística são diferentes de zero.

O teste GOF resultou em um p-valor de 0,1184 , que é não significativo. Assim, não se pode rejeitar a hipótese nula de que há associação entre as frequências observadas e as previstas. Logo, de acordo com Fávero (2014), o modelo apresentou um bom ajuste.

A Tabela 3 também é composta pelo resultado da estimação dos parâmetros da regressão logística das variáveis explicativas, que compõem as quatro hipóteses de pesquisa. Essas hipóteses foram formuladas para a explicação dos fatores ambientais que impactam na probabilidade de gestores públicos municipais do Estado de Goiás serem incluídos na lista de inelegíveis. Esses resultados, em confronto com as hipóteses de pesquisa, serão discutidos a seguir.

A Hipótese H1 infere uma relação positiva entre o tamanho da população eleitoral e a inclusão na lista de inelegíveis. Os resultados da regressão logística sugerem uma proposição contrária. Com um coeficiente negativo de $-0,1650311$ estimado para a variável Tam e significativo a $5 \%$, a probabilidade de inclusão dos agentes públicos aumenta nas cidades com menor população eleitoral.

Esse resultado contraria plenamente a hipótese de pesquisa H1. Portanto, rejeita-se a hipótese de que quanto maior o tamanho da população eleitoral, maior é a probabilidade da inclusão do gestor na lista de inelegíveis.

Porém, estão condizentes com Nobre (2010), o qual identificou que no Estado do Ceará, no período de 2001 a 2004, o percentual de desaprovação das contas municipais de gestão da saúde é mais frequente nos municípios de pequeno porte, que representam $70,2 \%$ dos municípios cearenses.

Além disso, Kronbauer et al. (2011) identificaram que, de forma geral, o Tribunal de Contas do Estado de Rio Grande do Sul fez mais apontamentos de inconformidades em municípios mais populosos do que ao contrário, quando da análise da prestação de contas de poderes executivos de municípios gaúchos no ano de 2004. Entretanto, no mesmo estudo, os autores verificaram que essa situação pode se inverter quando se faz a separação por regiões de abrangência da Corte. Por exemplo, na região noroeste do Estado do Rio Grande do Sul, a população média dos municípios que apresentaram mais inconformidades era inferior aos municípios com menos inconformidades. Porém, os resultados encontrados pelo autor não apresentaram significância estatística.

Por outro lado, os achados desta pesquisa contrariam os de Velten (2015), que estudou os determinantes que influenciam na rejeição das contas municipais. Segundo o autor, os municípios capixabas que possuem maior população apresentam maior probabilidade de rejeição das contas anuais, valores significativos a 1\%. A conclusão do autor é a de que em razão de administrarem mais recursos públicos, estão expostos à uma maior incidência de erros administrativos.

Os resultados encontrados também contrariam Albuquerque (2016), que verificou uma relação positiva, mas não significativa, entre os municípios mais populosos do interior do Amazonas e a frequência de rejeição das contas anuais dos poderes executivos municipais. Do mesmo modo, Milanezi e Mont-Mor (2017), assim como Laureano e Macagnan (2017) encontraram relação positiva entre o tamanho da população e a probabilidade de rejeição das contas municipais, mas sem significância estatística.

A Hipótese H2 pressupõe uma relação positiva entre a distância do município até a capital e a inclusão na lista de inelegíveis. O coeficiente estimado apresentou um valor positivo de 0,0024548 e confirmou a relação positiva da variável Dist. Além disso, se apresentou estatisticamente significativo a $1 \%$. Portanto, não se pode rejeitar a hipótese $\mathrm{H} 2$ de que quanto maior é a distância do município em relação ao órgão de Controle Externo, maior é a probabilidade de inclusão do gestor na lista de inelegíveis.

$\mathrm{O}$ achado sugere duas proposições. Primeiramente, a de que uma maior distância em relação ao órgão de controle favorece o comportamento oportunístico dos gestores. Em razão disso, pressupõe-se que os gestores cometam mais irregularidades, que só são verificadas a posteriori, no julgamento do processo de prestação de contas.

Esses resultados convergem para o trabalho de Campante e Do (2014), no qual identificaram que os níveis de corrupção mais elevados são encontrados nas cidades americanas mais isoladas de grandes centros urbanos. Segundo os autores isso ocorre em razão de haver uma menor accountability nessas cidades. Ademais, os meios de comunicação locais fazem uma cobertura menos intensa das ações dos governos dessas cidades, de forma que os cidadãos se tornam menos informados e menos ativos sobre os acontecimentos da política local. Nesse sentido, os autores revelam que cidades isoladas ou mais distantes da capital exigem uma vigilância extra, pois possuem uma reduzida accountability e também porque os cidadãos estão menos preocupados com a política local. A segunda é a de que municípios mais próximos da capital são beneficiados em razão do lobby político, facilitado pela proximidade da sede do órgão de Controle Externo.

Du, Tang e Young (2012) afirmam que a proximidade geográfica favorece a percepção de uma identidade social entre as pessoas, facilita a relação social e melhora a comunicação. Os autores verificaram que os executivos das empresas públicas mais próximas da agência central de controle, com sede na capital, 
obtiveram maior pontuação na avaliação de desempenho, quando comparados com executivos de empresas mais distantes. Para os autores, uma maior proximidade entre controladores e executivos levou a ser empregado um maior grau de subjetividade na avaliação.

Os resultados encontrados no presente trabalho divergem de Laureano (2016), Laureano e Macagnan (2017) e Miranda Júnior (2010). Segundo Laureano (2016), a proximidade geográfica de um município em relação à Capital não favorece o lobby político que pode influenciar as decisões de Tribunais de Contas. Laureano (2016) e Laureano e Macagnan (2017) não encontraram relação significativa entre a distância e a probabilidade de ser emitido um parecer desfavorável acerca das contas municipais dos municípios gaúchos. Do mesmo modo, Miranda Júnior (2010) não encontrou relação significativa entre os níveis de corrupção municipais e a distância das cidades em relação à respectiva capital estadual.

A Hipótese H3 infere uma relação negativa entre o IDHm e a inclusão na lista de inelegíveis. O coeficiente da regressão logística, no valor de -0,2012193, confirmou a relação inversa e negativa da variável $I D H m$, mas o resultado encontrado não foi significativo. Considerando que a regressão levou a um resultado não significativo, não se pode aceitar a hipótese H3 de que quanto menor é o IDHm municipal, maior é a probabilidade da inclusão do gestor na lista de inelegíveis.

Os resultados podem ser reforçados pelo estudo de Silva e Revorêdo (2005), que verificaram que variáveis socioeconômicas não influenciam diretamente as decisões de Tribunais de Contas. Uma justificativa apresentada pelos autores é que os aspectos legais dos julgamentos são mais relevantes que a eficácia, eficiência e efetividade, as quais tem um impacto maior no cidadão e poderiam influenciar nos indicadores sociais.

Albuquerque (2016) encontrou um resultado semelhante e não significativo. O autor percebeu que a ocorrência de inconformidades dos poderes executivos municipais do Amazonas é maior nos municípios que apresentam um menor IDHm. No caso em comento, o p-valor encontrado para a variável IDHm foi de 0,0851, que poderia ser significativo a 10\%, caso o autor houvesse adotado um critério mais flexível.

Por outro lado, Glaser e Saks (2006) encontraram uma relação positiva e significativa entre os níveis de desigualdade social e a corrupção. Ou seja, nos Estados americanos que apresentam maior desigualdade social há um nível mais elevado de corrupção. Logo, está em consonância os resultados encontrados, pois níveis mais elevados de corrupção sugerem uma maior incidência de irregularidades na administração pública.

Entretanto, a relação encontrada, ainda que não significante estatisticamente, contrariam os resultados de Santos et al. (2016). Para os autores, um melhor IDH municipal aumenta a probabilidade de ocorrência de ressalvas em pareceres de prestações de contas. Percebe-se, portanto, que os resultados são controversos, razão pela qual se deve continuar estudando o comportamento da variável de desenvolvimento humano em futuras pesquisas.

A Hipótese H4 estabelece uma relação positiva entre o ano eleitoral e a inclusão na lista de inelegíveis. Segundo os dados da Tabela 3, o ano eleitoral é fator preponderante para o aumento da probabilidade de inclusão de gestores municipais na lista de inelegíveis. O coeficiente da variável $A n o E$ apresentou valor positivo de 0,8676894 e significativo a 1\%. Consequentemente, os gestores têm maior chance de constar no rol de inelegíveis. Portanto, não se pode rejeitar a hipótese H4 de que o ano eleitoral aumenta a probabilidade da inclusão do gestor na lista de inelegíveis.

$\mathrm{O}$ ano de eleições municipais é ano de turbulência no que se refere à gestão pública. Primeiro, porque cria uma expectativa de reeleição daquele gestor que já está no poder e é candidato à reeleição. Segundo, porque oferece um risco à atual gestão, um risco de descontinuidade da administração na hipótese de não reeleição. Além disso, a eleição de um opositor é outro risco à atual administração.

A ocorrência de irregularidades pode advir do uso da máquina pública para o financiamento da companha, através do gasto indevido de recursos públicos ou da utilização de estratégias para convencimento do eleitorado, como a inaugurações de obras inacabadas ou serviços públicos indisponíveis próximos ao pleito eleitoral.

Em uma pesquisa realizada nos municípios da Espanha, os autores Garcia-Sanchez, Mordán e Cuadrado-Ballesteros (2014) destacam que é importante monitorar os políticos nos momentos que antecedem as eleições, porque a proximidade eleitoral prejudica a saúde financeiras dos governos locais, reduzindo consideravelmente a solvência de curto e longo prazos. Além disso, segundo os autores, a insolvência financeira provocada pelo comportamento oportunista reduz o bem-estar dos cidadãos, em razão da diminuição da capacidade de prestar serviços públicos.

Desse modo, traçando um paralelo com a Teoria da Agência (JENSEN; MECKLING, 1976), o comportamento oportunista dos agentes acaba por prejudicar os interesses do principal, que são os eleitores.

A redução da solvência pode ser explicada pelo comportamento oportunista dos gestores, que é despertado no período pré-eleitoral com o objetivo de satisfazer os eleitores e assim, aumentar a popularidade e a possibilidade de reeleição (GARCIA-SANCHEZ; MORDÁN; CUADRADO-BALLESTEROS, 2014; TELLIER, 2006).

Por sua vez, Tellier (2006) observou nas províncias canadenses, que a ação oportunística dos governantes é mais evidente quando são pequenas as chances de vencer as próximas eleições, fato que os leva a aumentarem as despesas públicas. Em razão disso, é importante que os resultados dos relatórios de 
auditoria de contas públicas sejam divulgados antes do período eleitoral. De acordo com Ferraz e Finan (2008), informações sobre corrupção nas contas públicas melhora a percepção do eleitor sobre a accountability e impacta diretamente no resultado da eleição, chegando a reduzir a chance de reeleição em até $7 \%$ em decorrência da divulgação de irregularidades.

Entretanto, em uma perspectiva distinta, ressalva-se que Nobre (2010) verificou que houve uma maior incidência de rejeições de contas de gestores públicos nos dois primeiros anos do mandato dos municípios do Estado do Ceará, período que não coincide com o ano eleitoral.

\section{Considerações Finais}

O objetivo desta pesquisa foi verificar, a partir da análise do dano ao erário, quais são os fatores ambientais que impactam na probabilidade de gestores municipais do Estado de Goiás serem incluídos na lista de inelegíveis. Mais especificamente, a partir de processos de prestação de contas de gestores de poderes executivos municipais junto ao Tribunal de Contas dos Municípios do Estado de Goiás.

Para tanto, utilizou-se da literatura empírica relacionada ao tema e também com o auxílio da Teoria da Agência para a construção das hipóteses de pesquisa sob a perspectiva da relação entre o gestor e o eleitor. A relação entre o gestor e o eleitor inicia com o processo eleitoral para a escolha de um representante, que tem o compromisso de buscar a satisfação dos interesses de um grupo local de indivíduos, com características exclusivas desse município.

Para identificar os fatores que impactam na probabilidade de inclusão dos gestores municipais na lista de inelegíveis foram utilizados dados de julgamentos de 612 processos de prestações de contas de gestão autuados entre 2008 e 2016 e relacionados a 240 municípios do Estado de Goiás.

A partir desses dados, foi estimado o modelo de regressão logística binária, para fins de mensuração da probabilidade de inelegibilidade. A variável dependente refere-se à inclusão na lista de inelegíveis e as outras quatro variáveis independentes que compuseram o modelo estão relacionadas à relação entre o gestor e o eleitor (variáveis ambientais). A estimação permitiu testar as quatro hipóteses elaboradas, sendo que as hipóteses $\mathrm{H} 1$ e H3 não podem ser aceitas e as hipóteses $\mathrm{H} 2$ e H4 não podem ser rejeitadas.

As variáveis relacionadas ao tamanho da população eleitoral e IDHm não exerceram impacto na inclusão de gestores públicos municipais na lista de inelegíveis. Por outro lado, as variáveis distância do município em relação à Capital e ano eleitoral exerceram influência e contribuíram para que os agentes públicos municipais fossem incluídos na lista de inelegíveis.

Esses resultados reforçam a importância do papel dos Tribunais de Contas, que através da sua função fiscalizadora tem a competência para julgar os responsáveis pelo uso do dinheiro público, e ao mesmo tempo informar a Justiça Eleitoral para que o mau administrador possa ser afastado do processo eleitoral, protegendo os interesses do cidadão e fortalecendo a democracia.

Além disso, destaca a atenção que deve ser dada ao gasto público no período eleitoral, no qual há uma maior probabilidade de as prestações de contas desse exercício impactarem na inelegibilidade do gestor público. Mas, ao mesmo tempo é o momento que o eleitor deve estar atualizado com os julgados dos Tribunais de Contas, para que possa escolher com propriedade o seu representante através das urnas.

O estudo também revela que os municípios mais distantes da Capital apresentaram maior probabilidade de terem seus gestores incluídos na lista de inelegíveis. Nesse caso, para a melhoria da gestão pública é necessária uma atuação incisiva do controle social sobre a atuação do gestor público, com informações idôneas e tempestivas da mídia local. Uma maior accountability da gestão dessas cidades auxiliaria nesse processo de controle social, como destacado por Campante e Do (2014), apoiado por um monitoramento específico por parte dos Tribunais de Contas em relação às cidades mais distantes do órgão de controle.

Como limitação desta pesquisa, têm-se que as alterações da plataforma de dados e layout dos relatórios não permitiram a análise dos dados dos processos autuados antes de 2008. Outra limitação é que este estudo considerou apenas as decisões de mérito, não contemplando a influência de recursos administrativos e decisões judiciais liminares para a exclusão dos gestores da lista de inelegíveis. Portanto, considerando o recorte dos dados, as análises são restritas à amostra selecionada, de modo que as conclusões não podem ser generalizadas indiscriminadamente para todos os processos de prestação de contas (administração indireta e Poder Legislativo), apenas para processos com imputação de débito do Tribunal de Contas dos Municípios do Estado de Goiás.

Do ponto de vista prático, o presente estudo pode colaborar com a evidenciação da importância do papel dos Tribunais de Contas no que tange a sua competência fiscalizadora e julgadora dos responsáveis por recursos públicos, podendo afastar os candidatos que tenham causado prejuízo ao patrimônio público do processo eleitoral democrático. Sob o aspecto teórico, contribui com a expansão da literatura acerca da inelegibilidade de agentes públicos e o controle externo da administração pública.

Por fim, para futuras pesquisas, sugere-se a ampliação da amostra com a utilização de informações de mais de um Tribunal de Contas, a expansão para o Poder Legislativo e demais órgãos da administração pública, a continuidade do debate com a adoção das variáveis estudadas e de outras variáveis socioeconômicas, como por exemplo, o Produto Interno Bruto dos Municípios, a renda per capta e os 
indicadores de qualidade municipal em educação, saúde e segurança. Também será válida a inclusão de fatores característicos dos gestores e membros da Cortes de Contas, como por exemplo, sexo, idade, nível de escolaridade, partido político do gestor público, origem técnica ou política do Conselheiro. Além disso, recomenda-se a inclusão de variáveis processuais como tempo de tramitação dos processos, quantidade de recursos administrativos, concessão de liminares judiciais e comparação das decisões com o posicionamento da opinião técnica em pareceres de Tribunais de Contas.

\section{Referências}

AGHION, Philippe; TIROLE, Jean. Formal and real authority in organizations. Journal of Political Economy, v. 105, n. 1, p. 1-29, 1997. DOI: https://doi.org/10.1086/262063. Disponível em: https://www.journals.uchicago.edu/doi/10.1086/262063. Acesso em: 03 nov. 2017.

ALBUQUERQUE, Martha D. G. Análise das inconsistências apontadas pelo TCE-AM nas prestações de contas anuais dos executivos municipais: uma abordagem ao controle externo. Orientador: Milanez Silva de Souza. 2016. 144 f. Dissertação (Mestrado Profissional em Contabilidade e Controladoria) - Universidade Federal do Amazonas, Manaus, 2016. Disponível em: https://tede.ufam.edu.br/handle/tede/5433. Acesso em: 19 mar. 2017.

AMERICAN ACCOUNTING ASSOCIATION. Report of the Committee on Accounting in the Public Sector, 1974-76. The Accounting Review, v. 52, n. 1, p. 33-52, 1977. Disponível em: https://www.jstor.org/stable/245505. Acesso em: 14 mar. 2017.

ARATO, Andrew. Representação, soberania popular e accountability. Revista Lua Nova, v. 55/56, p. 85103, 2002. DOI: https://doi.org/10.1590/S0102-64452002000100004. Disponível em: http://www.scielo.br/scielo.php?script=sci_arttext\&pid=S0102-64452002000100004\&lng=pt\&tlng=pt. Acesso em: 10 abr. 2017.

BOYCE, Gordon; DAVIDS, Cindy. Conflict of interest in policing and the public sector. Public Management Review, v. 11, n. 5, p. 601-640, 2009. DOI: https://doi.org/10.1080/14719030902798255. Disponível em: https://www.tandfonline.com/doi/abs/10.1080/14719030902798255. Acesso em: 02 nov. 2017.

BRASIL. Lei no 9.504, de 30 de setembro de 1997. Estabelece normas para as eleições. Brasília, DF: Presidência da República. Disponível em: http://www.planalto.gov.br/ccivil_03/leis/L9504.htm. Acesso em: 12 mar. 2017.

BRASIL. Lei Complementar no 135, de 4 de junho de 2010. Altera a Lei Complementar no 64, de 18 de maio de 1990, que estabelece, de acordo com o $\S 9^{\circ}$ do art. 14 da Constituição Federal, casos de inelegibilidade, prazos de cessação e determina outras providências, para incluir hipóteses de inelegibilidade que visam a proteger a probidade administrativa e a moralidade no exercício do mandato. Disponível em: http://www.planalto.gov.br/ccivil_03/leis/lcp/lcp135.htm. Acesso em: 12 mar. 2017.

CALABRO, Andrea; TORCHIA, Mariateresa. Conflicts of Interest and Governance Mechanisms in Italian Local Public Utilities. International Journal of Public Administration, v. 34, n. 7, p. 447-460, 2011. DOI: https://doi.org/10.1080/01900692.2011.576215. Disponível em: https://www.tandfonline.com/doi/abs/10.1080/01900692.2011.576215. Acesso em: 01 nov. 2017.

CAMPANTE, Filipe R.; DO, Quoc-Anh. Isolated capital cities, accountability, and corruption: evidence from US States. American Economic Review, v. 104, n. 8, p. 2456-2481, 2014. DOI: https://doi.org/10.1257/aer.104.8.2456. Disponível em: https://www.aeaweb.org/articles?id=10.1257/aer.104.8.2456. Acesso em: 27 mar. 2017.

CONSELHO FEDERAL DE CONTABILIDADE. CFC. NBC TSP estrutura conceitual, 2016. Disponível em: http://www1.cfc.org.br/sisweb/SRE/docs/NBCTSPEC.doc. Acesso em: 11 mar. 2017.

DU, Fei; TANG, Guliang; YOUNG, S. Mark. Influence activities and favoritism in subjective performance evaluation: evidence from chinese state-owned enterprises. Accounting Review, v. 87, n. 5, p. 1555-1588, 2012. DOI: https://doi.org/10.2308/accr-50196. Disponível em: https://aaajournals.org/doi/10.2308/accr50196. Acesso em: 03 nov. 2017.

FÁVERO, Luiz P. Manual de análise de dados. Rio de Janeiro: Elsevier, 2017.

FÁVERO, Luiz P. Métodos quantitativos com Stata. Rio de Janeiro: Elsevier, 2014. 
FERRAZ, Claudio; FINAN, Frederico. Exposing corrupt politicians: the effects of Brazil's publicly released audits on electoral outcomes. Quarterly Journal of Economics, v. 123, n. 2, p. 703-745, 2008. DOI: https://doi.org/10.1162/qjec.2008.123.2.703. Disponível em: https://academic.oup.com/qje/articleabstract/123/2/703/1930865? redirectedFrom=fulltext. Acesso em: 19 mar. 2017.

GARCIA-SÁNCHEZ, Isabel-María; MORDÁN, Noemí; CUADRADO-BALLESTEROS, Beatriz. Do electoral cycles affect local financial health? Policy Studies, v. 35, n. 6, p. 533-556, 2014. DOI:

https://doi.org/10.1080/01442872.2014.971727. Disponível em:

https://www.tandfonline.com/doi/abs/10.1080/01442872.2014.971727. Acesso em: 27 nov. 2017.

GLAESER, Edward. L.; SAKS, Raven. E. Corruption in America. Journal of Public Economics, v. 90, n. 6-7, p. 1053-1072, 2006. DOI: https://doi.org/10.1016/j.jpubeco.2005.08.007. Disponível em:

https://www.sciencedirect.com/science/article/abs/pii/S004727270500126X?via\%3Dihub. Acesso em: 27 nov. 2017.

HEFETZ, Amir; WARNER, Mildred. Privatization and Its Reverse: Explaining the Dynamics of the Government Contracting Process. Journal of Public Administration Research and Theory, v. 14, n. 2, p. 171-190, 2004. DOI: https://doi.org/10.1093/jopart/muh012. Disponível em:

https://academic.oup.com/jpart/article-abstract/14/2/171/1004807?redirectedFrom=fulltext. Acesso em 16 nov. 2017.

HILBE, Joseph M. Logistic Regression Models. New York: CRC Press, 2009.

INGRAM, Robert W.; COPELAND, Ronald M. Municipal accounting information and voting behavior. The Accounting Review, v. 56, n. 4, p. 830-843, 1981. Disponível em: https://www.jstor.org/stable/247204. Acesso em: 14 mar. 2017.

INSTITUTO MAURO BORGES. IMB. Perfil socioeconômico dos municípios goianos. Disponível em: http://www.imb.go.gov.br. Acesso em: 7 mai. 2017.

JENSEN, Michael C.; MECKLING, William H. Theory of the firm: managerial behavior, agency costs and ownership structure. Journal of Financial Economics, v. 3, n. 4, p. 305-360, 1976. DOI:

https://doi.org/10.1016/0304-405X(76)90026-X. Disponível em:

https://www.sciencedirect.com/science/article/pii/0304405X7690026X?via\%3Dihub. Acesso em: 15 mar. 2017.

KELLY, Rita M. An inclusive democratic polity, representative bureaucracies, and the new public management. Public Administration Review, v. 58, n. 3, p. 201-208, 1998. Disponível em: https://www.jstor.org/stable/976560. Acesso em: 15 nov. 2017.

KRONBAUER, C., KRÜGER, G., OTT, E., NASCIMENTO, C. Análise de inconsistências apontadas pelo TCE/RS em auditorias municipais: estudo do controle externo da gestão pública. Revista de Contabilidade e Organizações, v. 5, n. 12, p. 48-71, 2011. DOI: https://doi.org/10.11606/rco.v5i12.34794. Disponível em: http://www.revistas.usp.br/rco/article/view/34794. Acesso em: 01 fev. 2017.

LANE, Jan-Erik. The principal-agent approach to politics: policy implementation and public policy-making. Open Journal of Political Science, v. 310, n. 2, p. 85-89, 2013. DOI: https://doi.org/10.4236/ojps.2013.32012. Disponível em: https://www.scirp.org/journal/paperinformation.aspx?paperid=30539. Acesso em: 15 mar. 2017.

\footnotetext{
LAUREANO, Rodrigo V. Fatores institucionais explicativos das decisões do TCE-RS sobre as prestações de contas dos prefeitos municipais. Orientador: Clea Beatriz Macagnan. 2016. Dissertação (Mestrado em Ciências Contábeis) - Universidade do Vale do Rio dos Sinos, São Leopoldo, 2016. 91 f. Disponível em: http://www.repositorio.jesuita.org.br/handle/UNISINOS/6226. Acesso em: 10 jun. 2017.

LAUREANO, Rodrigo V.; MACAGNAN, Clea B. Fatores institucionais explicativos para as decisões do TCE-RS sobre as prestações de contas dos prefeitos municipais. In: XI CONGRESSO ANPCONT, 2017, Belo Horizonte. Anais... Belo Horizonte: Anpcont, 2017. Disponível em: $\mathrm{http}: / / c o n g r e s s o s$.anpcont.org.br/xi/anais/artigo/cpt-786-fatores-institucionais-explicativos-para-as-decisoesdo-tce-rs-sobre-as-prestacoes-de-contas-dos-prefeitos-municipais. Acesso em: 16 jun. 2017.
}

MANIN, Bernard; PRZEWORSKI, Adam; STOKES, Susan C. Eleições e representação. Lua Nova: Revista 
de Cultura e Política, n. 67, p. 105-138, 2006. DOI: https://doi.org/10.1590/S0102-64452006000200005. Disponível em: http://www.scielo.br/scielo.php?script=sci_arttext\&pid=S0102-

64452006000200005\&lng=pt\&tIng=pt. Acesso em: 06 abr. 2017.

MILANEZI, Angelo R.; MONTE-MOR, Danilo S. O efeito da utilização de créditos adicionais suplementares no julgamento das contas anuais dos municípios capixabas. In: XI Congresso Anpcont, 2017, Belo Horizonte. Anais... Belo Horizonte: Anpcont, 2017. Disponível em:

http://congressos.anpcont.org.br/xi/anais/artigo/cpt-675-o-efeito-da-utilizacao-de-creditos-adicionaissuplementares-no-julgamento-das-contas-anuais-dos-municipios-capixabas. Acesso em: 16 jun. 2017.

MIRANDA JÚNIOR, José C. A corrupção nos municípios brasileiros: uma análise a partir dos relatórios de fiscalização produzidos pela Controladoria Geral da União. Orientador: Paulo Augusto Pettenuzzo de Britto. 2010. 52 f. Dissertação (Mestrado Profissional em Economia) - Universidade de Brasília, Brasília, 2010. Disponível em: http://repositorio.unb.br/handle/10482/9660. Acesso em 23 fev. 2017.

NOBRE, Leni. L. L. Análise dos julgamentos do Tribunal de Contas dos Municípios do Estado do Ceará: um olhar sobre a prestação de contas dos sistemas municipais de saúde. Orientador: Cláudio Gastão Junqueira de Castro. 2010. 198 f. Tese (Doutorado em Saúde Pública) - Universidade de São Paulo, São Paulo, 2010. DOI: https://doi.org/10.11606/T.6.2010.tde-13072010-100331. Disponível em: https://teses.usp.br/teses/disponiveis/6/6135/tde-13072010-100331/pt-br.php. Acesso em: 11 mar. 2017.

PEREIRA, Jeronimo R. T. Gestão e Controle de Recursos Públicos - um estudo sobre a rejeição de prestação de contas nos governos municipais do Estado da Bahia. Orientador: José Bernardo Cordeiro Filho. 2010. 112 f. Dissertação (Mestrado em Ciências Contábeis) - Universidade Federal da Bahia, Salvador, 2010. Disponível em: http://repositorio.ufba.br/ri/handle/ri/7428. Acesso em 11 mar. 2017.

PEREIRA, Jeronimo R. T.; CORDEIRO FILHO, José B. Rejeições de prestação de contas de governos municipais: o que está acontecendo? Contabilidade, Gestão e Governança, v. 15, n. 1, p. 33-43, 2012. Disponível em: https://www.revistacgg.org/contabil/article/view/393. Acesso em: 16 mar. 2017.

\section{PEREIRA, Luiz C. B.; SPINK, Peter. Reforma do Estado e administração pública gerencial. FGV} Editora, 2014.

POLLITT, Christopher; SUMMA, Hilkka. Reflexive Watchdogs? How Supreme Audit Institutions Account for Themselves. Public Administration, v. 75, Summer, p. 313-336, 1997. DOI: https://doi.org/10.1111/14679299.00063. Disponível em: https://onlinelibrary.wiley.com/doi/abs/10.1111/1467-9299.00063. Acesso em: 06 nov. 2017.

RIBEIRO FILHO, Antônio D. Os efeitos do período de transição governamental nas contas públicas: uma análise em Municípios, Estados e União. 2011. 213 f. Dissertação (Mestrado em Ciências Contábeis) - Universidade de Brasília, Brasília, 2011. Disponível em: http://repositorio.unb.br/handle/10482/9283. Acesso em: 23 fev. 2017.

SANTOS, Carla. M. V., PIMENTA, M. M; RANGEL, T. P.; OHAYON, P. Características dos municípios fluminenses e suas falhas ressalvadas nos pareceres de prestação de contas do TCE-RJ. Pensar Contábil, v. 18, n. 67, p. 41-48, 2016. Disponível em: http://www.atena.org.br/revista/ojs-2.2.306/index.php/pensarcontabil/article/view/2946. Acesso em: 19 mar. 2017.

SILVA, César A. T.; REVORÊDO, Wirla C. Economicidade da gestão pública municipal: um estudo das decisões do Tribunal de Contas do Estado de Pernambuco. Revista Universo Contábil, v. 1, n. 2, p. 9-22, 2005. DOI: http://dx.doi.org/10.4270/ruc.20051. Disponível em:

https://proxy.furb.br/ojs/index.php/universocontabil/article/view/88. Acesso em: 01 fev. 2017.

STREIM, Hannes. Agency problems in the legal political system and supreme auditing institutions.

European Journal of Law and Economics, v. 1, n. 3, p. 177-191, 1994. DOI:

https://doi.org/10.1007/BF01552469. Disponível em: https://link.springer.com/article/10.1007/BF01552469. Acesso em: 14 mar. 2017.

TELLIER, Geneviève. Public Expenditures in Canadian Provinces: An Empirical Study of Politico-Economic Interactions. Public Choice, v. 126, n. 3/4, p. 367-385, 2006. DOI: https://doi.org/10.1007/s11127-0062455-x. Disponível em: https://link.springer.com/article/10.1007\%2Fs11127-006-2455-x. Acesso em: 27 nov. 2017. 
TRIBUNAL DE CONTAS DOS MUNICÍPIOS DO ESTADO DE GOIÁS. TCMGO. Resolução Administrativa n. 107, de 1 de agosto de 2016. 2016. Dispõe sobre a homologação da relação de agentes públicos com contas julgadas irregulares ou com parecer pela rejeição, apreciadas por este Tribunal entre 02/10/2008 e 08/07/2016. Goiânia: TCMGO. Disponível em: https://www.tcmgo.tc.br/site/legislacao/resolucoesadministrativas-por-ano/resolucoes-administrativas-2016/ Acesso em: 14 mai. 2017.

TRIBUNAL REGIONAL ELEITORAL. TRE-GO. Relação de agentes públicos com contas julgadas irregulares ou com parecer pela rejeição. 2016. Disponível em:

http://www.justicaeleitoral.jus.br/arquivos/tre-go-tcm-atualizacao-do-dia-11-11-2016-da-relacao-de-agentespublicos-com-contas-julgadas-irregulares-ou-com-parecer-pela-

rejeicao/rybena_pdf?file=http://www.justicaeleitoral.jus.br/arquivos/tre-go-tcm-atualizacao-do-dia-11-112016-da-relacao-de-agentes-publicos-com-contas-julgadas-irregulares-ou-com-parecer-pela-

rejeicao/at_download/file. Acesso em: 19 mai.2017.

TRIBUNAL SUPERIOR ELEITORAL. TSE. Eleições anteriores. 2016. Disponível em:

http://www.tse.jus.br/eleicoes/eleicoes-anteriores/eleicoes-anteriores. Acesso em: 01 dez. 2016.

VELTEN, Simone R. Determinantes da rejeição das prestações de contas anuais dos municípios capixabas pelo Tribunal de Contas do Espírito Santo. Orientador: Fábio Moraes da Costa. 2015. 98 f. Dissertação (Mestrado em Ciências Contábeis) - Fundação Instituto Capixaba de Pesquisas em Contabilidade, Economia e Finanças - FUCAPE, Espírito Santo, 2015. Disponível em:

http://www.fucape.br/_public/producao_cientifica/8/Disserta\%C3\%A7\%C3\%A3o-

\%20Simone\%20Reinhols.pdf. Acesso em: 16 jun. 2017.

\section{NOTAS}

\section{AGRADECIMENTOS}

Não se aplica.

\section{CONTRIBUIÇÃO DE AUTORIA}

Concepção e elaboração do manuscrito: R. S. Cella, M.R.R. Machado

Coleta de dados: R. S. Cella

Análise de dados: R. S. Cella, M.R.R. Machado

Discussão dos resultados: R. S. Cella, M.R.R. Machado

Revisão e aprovação: R. S. Cella, M.R.R. Machado

\section{CONJUNTO DE DADOS DE PESQUISA}

O conjunto de dados que dá suporte aos resultados deste estudo não está disponível publicamente.

\section{FINANCIAMENTO}

Não se aplica.

\section{CONSENTIMENTO DE USO DE IMAGEM}

Não se aplica.

\section{APROVAÇÃO DE COMITÊ DE ÉTICA EM PESQUISA}

Não se aplica.

\section{CONFLITO DE INTERESSES}

Não se aplica.

\section{LICENÇA DE USO}

Os Direitos Autorais para artigos publicados neste periódico são do autor, com direitos de primeira publicação para a Revista. Em virtude de aparecerem nesta Revista de acesso público, os artigos são de uso gratuito, com atribuições próprias, em aplicações educacionais, de exercício profissional e para gestão pública. A Revista adotou a licença Creative Commons Atribuição 4.0 Internacional - CC BY NC ND. Esta licença permite acessar, baixar (download), copiar, imprimir, compartilhar, reutilizar e distribuir os artigos desde que com a citação da fonte, atribuindo os devidos créditos de autoria. Nesses casos, nenhuma permissão é necessária por parte dos autores ou dos editores. Autores têm autorização para assumir contratos adicionais separadamente, para distribuição não-exclusiva da versão do trabalho publicada nesta revista (ex.: publicar em repositório institucional ou um capítulo de livro). 


\section{PUBLISHER}

Universidade Federal de Santa Catarina. Curso de Ciências Contábeis e Programa de Pós-graduação em Contabilidade. Publicação no Portal de Periódicos UFSC. As ideias expressadas neste artigo são de responsabilidade de seus autores, não representando, necessariamente, a opinião dos editores ou da universidade.

\section{EDITORES}

Carlos Eduardo Facin Lavarda e Suliani Rover

\section{HISTÓRICO}

Recebido em: 26/12/2018 - Revisado por pares em: 08/04/2020 - Reformulado em: 20/04/2020 Recomendado para publicação em: 02/05/2020 - Publicado em: 30/05/2020 